\title{
The pobA gene of Burkholderia cenocepacia encodes a Group I Sfp-type phosphopantetheinyltransferase required for biosynthesis of the siderophores ornibactin and pyochelin
}

\author{
Atif H. Asghar,† Sravanthi Shastri, Emma Dave,‡ Irena Wowk, \\ Kirsty Agnoli,§ Anne M. Cook and Mark S. Thomas \\ Department of Infection and Immunity, The Medical School, University of Sheffield, Beech Hill Road, \\ Sheffield S10 2RX, UK
}

Correspondence

Mark S. Thomas

m.s.thomas@shef.ac.uk

Received 17 September 2010

Revised 17 October 2010

Accepted 19 October 2010
The opportunistic pathogen Burkholderia cenocepacia produces the siderophores ornibactin and pyochelin under iron-restricted conditions. Biosynthesis of both siderophores requires the involvement of non-ribosomal peptide synthetases (NRPSs). Using a transposon containing the lac $Z$ reporter gene, two $B$. cenocepacia mutants were isolated which were deficient in siderophore production. Mutant IW10 was shown to produce normal amounts of ornibactin but only trace amounts of pyochelin, whereas synthesis of both siderophores was abolished in AHA27. Growth of AHA27, but not IW10, was inhibited under iron-restricted conditions. In both mutants, the transposon had integrated into the $p o b A$ gene, which encodes a polypeptide exhibiting similarity to the Sfp-type phosphopantetheinyltransferases (PPTases). These enzymes are responsible for activation of NRPSs by the covalent attachment of the 4 ' -phosphopantetheine (P-pant) moiety of coenzyme A. Previously characterized PPTase genes from other bacteria were shown to efficiently complement both mutants for siderophore production when provided in trans. The $B$. cenocepacia pobA gene was also able to efficiently complement an Escherichia coli entD mutant for production of the siderophore enterobactin. Using mutant IW10, in which the lacZ gene carried by the transposon is inserted in the same orientation as $p o b A$, it was shown that pobA is not appreciably iron-regulated. Finally, we confirmed that Sfp-type bacterial PPTases can be subdivided into two distinct groups, and we present the amino acid signature sequences which characterize each of these groups.

\section{INTRODUCTION}

The genus Burkholderia includes a number of Gramnegative bacterial species that are pathogenic to animals

tPresent address: Department of Environmental and Health Research, University of Umm Al-Qura, Makkah, Saudi Arabia.

łPresent address: Discovery Biology, UCB, 216 Bath Road, Slough SL1 3WE, UK.

§Present address: Institut fur Pflanzenbiologie, Universität Zürich, 8008 Zürich, Switzerland.

Abbreviations: ACPS, holo-ACP synthase; ArCP, aryl carrier protein; $\mathrm{CF}$, cystic fibrosis; MCS, multiple cloning site; NRPS, non-ribosomal peptide synthetase; PCP, peptidyl carrier protein; PKS, polyketide synthetase; PPTase, phosphopantetheinyltransferase.

The GenBank/EMBL/DDBJ accession number for the sequence of the pobA region from B. cenocepacia strain $715 \mathrm{j}$ is D0398944.

Supplementary material, describing the construction of plasmids, and two supplementary figures are available with the online version of this paper. and/or plants (Mahenthiralingam et al., 2005; Compant et al., 2008). One group of closely related species, the Burkholderia cepacia complex (BCC), are noted for their ability to cause opportunistic infections in humans, particularly in patients with cystic fibrosis (CF) (LiPuma, 1998; Coenye et al., 2001; Speert, 2002; Mahenthiralingam et al., 2008). Among the members of the BCC, Burkholderia cenocepacia is the most prevalent in both $\mathrm{CF}$ and non-CF infections (Vandamme et al., 1997; Coenye et al., 2001; Mahenthiralingam et al., 2002, 2005; Reik et al., 2005). The complete genome sequence has recently been determined for a strain of $B$. cenocepacia that caused an epidemic among CF patients in Canada and the UK (Holden et al., 2009).

Colonization of the CF lung by bacterial pathogens requires the expression of high-affinity iron uptake systems due to the decreased availability of iron (Brown et al., 1984; Thompson et al., 1990; Gray-Owen \& Schryvers, 1996; Wang et al., 1996). A commonly employed mechanism for 
iron acquisition by bacteria is the secretion of lowmolecular-weight $\mathrm{Fe}(\mathrm{III})$-binding compounds known as siderophores, which are then transported into the bacterium via specific outer membrane receptors (Braun, 2001; Crosa \& Walsh, 2002). Most clinical isolates of $B$. cenocepacia produce the siderophores ornibactin and pyochelin (Sokol, 1986; Visca et al., 1993; Meyer et al., 1995; Darling et al., 1998; Thomas, 2007), and their production has been correlated with morbidity and mortality in CF patients and/or shown to contribute to pathology in animal models of respiratory infection (Sokol, 1986; Sokol \& Woods, 1988; Sokol et al., 1999, 2000; Visser et al., 2004; Uehlinger et al., 2009). Ornibactin contains an L-ornithine-D-hydroxyaspartate-L-serine-L-ornithine backbone that requires two non-ribosomal peptide synthetases (NRPSs), OrbI and OrbJ, for its assembly (Stephan et al., 1993; Agnoli et al., 2006). The yellow-green fluorescent siderophore pyochelin is biosynthesized from salicylate by the successive addition and cyclization of two molecules of cysteine (Ankenbauer et al., 1988; Reimmann et al., 1998; Quadri et al., 1999; Quadri, 2000; Crosa \& Walsh, 2002). This process requires two NRPSs, PchE and PchF (Quadri, 2000; Reimmann et al., 2001).

NRPSs have a modular arrangement, consisting mainly of repeated tri-domain elongation units ('modules'). Each module comprises (i) an amino acid adenylation domain (A), which serves to activate the amino acid building block; (ii) a peptidyl carrier protein (PCP) domain, which is derivatized with a 4 '-phosphopantetheine (P-pant) 'arm' of $\sim 20 \AA$ in length that is used, in turn, to covalently attach the amino acid to the NRPS via a thioester bond; and (iii) a condensation domain (C), which catalyses peptide bond formation between the phosphopantetheine-anchored amino acid in one module and a similarly anchored amino acid in the preceding unit (Quadri, 2000; Crosa \& Walsh, 2002; Challis \& Naismith, 2004; Sieber \& Marahiel, 2005). In situations where one of the building blocks is not an amino acid, such as occurs in pyochelin, which has an aryl $\mathrm{N}$-cap derived from salicylate, the PCP domain is substituted by an aryl carrier protein (ArCP) domain, as in the case of PchE. This domain is also a substrate for phosphopantetheinylation. Activation of NRPS PCP and ArCP domains is carried out by a phosphopantetheinyltransferase (PPTase). This enzyme transfers the P-pant moiety from coenzyme A (CoASH) to an invariant serine residue in the conserved phosphopantetheinylation site [FFxLGG(D/H)S(L/I)] of the PCP/ArCP domain (Walsh et al., 1997; Marahiel et al., 1997; Quadri et al., 1998b). A total of four predicted PCP domains are present in the ornibactin biosynthetic machinery (three in OrbI and one in OrbJ), each of which binds one of the four amino acid building blocks, and three PCP/ArCP domains occur in the NRPSs involved in pyochelin biosynthesis (two in PchE and one in PchF) (Quadri, 2000; Agnoli et al., 2006).

A well-characterized PPTase is the Escherichia coli EntD protein, which is required for activating the $\mathrm{ArCP}$ domain of EntB, and the PCP domain of EntF during biosynthesis of the catecholate siderophore enterobactin (Lambalot et al., 1996; Gehring et al., 1997). PPTases are also required for the activation of NRPSs and polyketide synthetases (PKSs) that participate in the biosynthesis of compounds other than siderophores (Walsh et al., 1997; Sieber \& Marahiel, 2003). For example, the Bacillus subtilis PPTase Sfp is required for the biosynthesis of surfactin, a cyclic lipopeptide possessing antibiotic properties, as well as for the catecholate siderophore bacillibactin (Nakano et al., 1992; Grossman et al., 1993; Quadri et al., 1998b; Heerklotz \& Seelig, 2001; May et al., 2001). PPTases such as EntD and Sfp, which play roles in secondary metabolism, are referred to as Sfp-type PPTases, and several different Sfp-type PPTases may be encoded by the same bacterium ( $\mathrm{Lu}$ et al., 2008).

In the majority of bacterial species, a second type of PPTase, known as holo-ACP synthase (ACPS) or AcpStype PPTase, is required for activation of acyl carrier protein $(\mathrm{ACP})$, a versatile protein that participates in the biosynthesis of fatty acids, phospholipids, lipid A, lipoic acid, RTX toxins, acylhomoserine lactones and the aldehyde substrate of bacterial luciferase (Lambalot \& Walsh, 1995; Flugel et al., 2000). The polypeptide chain length of AcpS-type PPTases $(\sim 120$ amino acids $)$ is approximately half that of Sfp-type PPTases and, unlike the monomeric Sfp-type PPTases, they form homotrimers. AcpS-type PPTases also activate the ACP domain(s) of PKSs but not those of NRPSs (Gehring et al., 1997). The Sfp-type PPTases produced by some bacteria (for example, EntD) cannot substitute for AcpS-type PPTases, and therefore in these bacteria the AcpS-type PPTase is essential for growth (Flugel et al., 2000). However, in some cases the Sfp-type PPTase can activate both NRPSs and ACP. For example, a Bacillus subtilis acpS mutant supports fatty acid biosynthesis, and Bacillus subtilis Sfp will modify E. coli or Bacillus subtilis apo-ACP in vitro (Quadri et al., 1998b; Mootz et al., 2001). In the case of Pseudomonas aeruginosa, the cross-reactivity of the Sfp-type PPTase is obligatory, as only the Sfp-type PPTase (PcpS) is present (Finking et al., 2002; Barekzi et al., 2004).

As part of our investigation into iron homeostasis in $B$. cenocepacia, we have used a novel transposon to isolate mutants that are unable to produce ornibactin and pyochelin. Characterization of the mutants has allowed us to infer that a single Sfp-type PPTase is required to activate the four NRPSs involved in biosynthesis of the two siderophores.

\section{METHODS}

Bacterial strains, media and growth conditions. All bacterial strains used are shown in Table 1. B. cenocepacia strains were cultured at $37{ }^{\circ} \mathrm{C}$ on M9 minimal salts agar (Clowes \& Hayes, 1968) containing glucose $(0.5 \%)$ as the carbon source, and subsequently maintained on this medium at room temperature $\left(\sim 20^{\circ} \mathrm{C}\right)$. E. coli strains were cultured at $37^{\circ} \mathrm{C}$ on MacConkey agar or on LB agar containing appropriate antibiotics for plasmid selection [IST agar (Oxoid) was used when the antibiotic was trimethoprim], and were 
Table 1. Bacterial strains, plasmids and transposons used in this study

Abbreviations: $\mathrm{Ap}^{\mathrm{R}}$, encodes ampicillin resistance; $\mathrm{Cm}^{\mathrm{R}}$, encodes chloramphenicol resistance; $\mathrm{Km}^{\mathrm{R}}$, encodes kanamycin resistance; $\mathrm{Tc}^{\mathrm{R}}$, encodes tetracycline resistance; $\mathrm{Rf}^{\mathrm{R}}$, rifampicin-resistant; $\mathrm{Sm}^{\mathrm{R}}$, streptomycin-resistant; $\mathrm{Tp}^{\mathrm{R}}$, trimethoprim-resistant or encodes trimethoprim resistance; $\mathrm{Pch}^{-}$, pyochelin-negative phenotype; $\mathrm{Orb}^{-}$, ornibactin-negative phenotype; $\mathrm{BHR}$, broad host range.

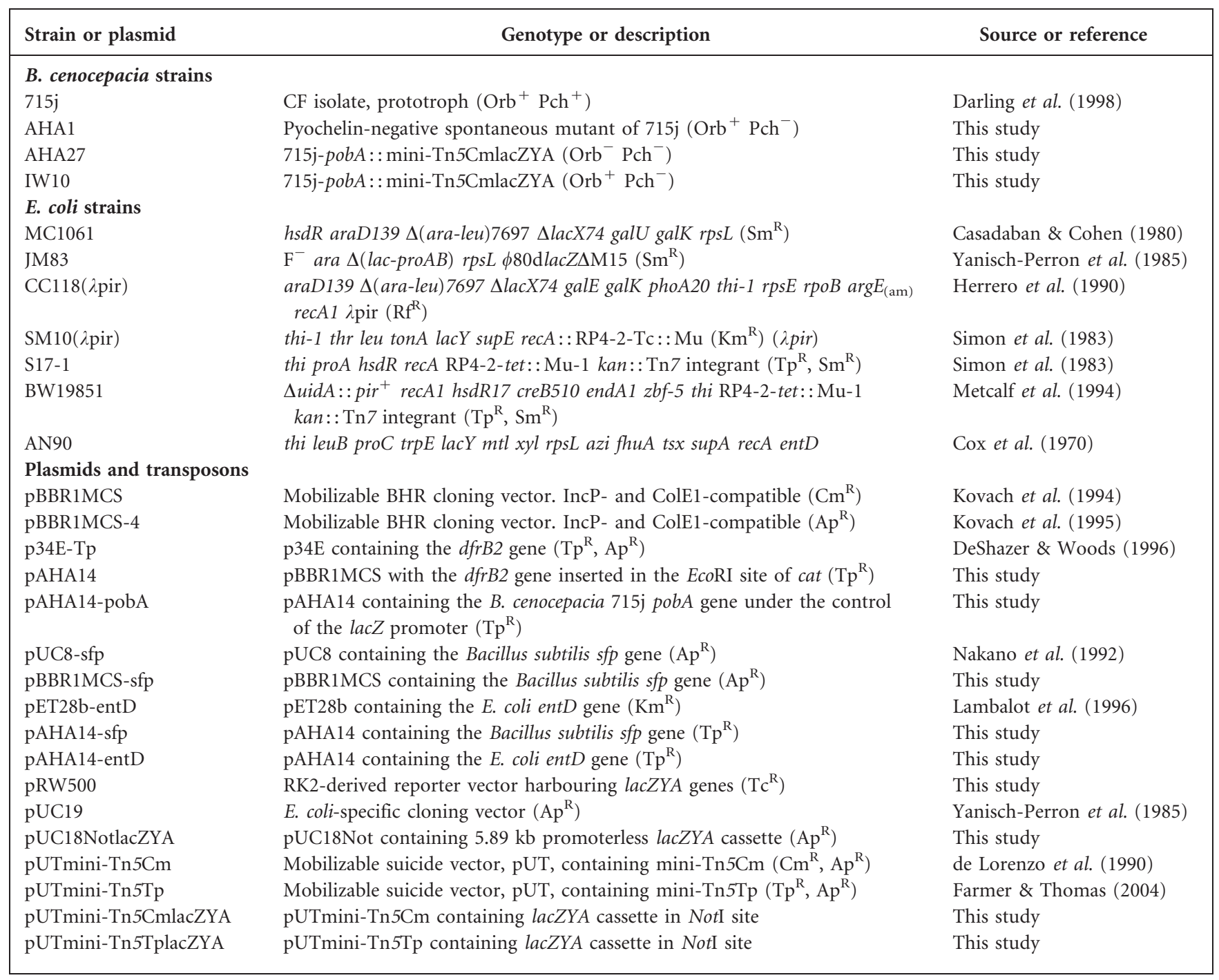

maintained at $4{ }^{\circ} \mathrm{C}$. Where indicated, casamino acids (CAA; Difco) were added to M9-glucose medium to a final concentration of $0.1 \%$, and is referred to as M9-CAA medium. Antibiotics were used at the following concentrations: ampicillin, $100 \mu \mathrm{g} \mathrm{ml}^{-1}$ (E. coli); trimethoprim, $25-50 \mu \mathrm{g} \mathrm{ml}^{-1}$ (E. coli and B. cenocepacia as indicated); chloramphenicol, $25 \mu \mathrm{g} \mathrm{ml}^{-1}$ (E. coli), $50 \mu \mathrm{g} \mathrm{ml}^{-1}$ for B. cenocepacia growing on LB medium and in M9-CAA medium, $100 \mu \mathrm{g} \mathrm{ml}^{-1}$ on M9-glucose agar; tetracycline (E. coli), $20 \mu \mathrm{g} \mathrm{ml}^{-1}$; kanamycin (E. coli), $25 \mu \mathrm{g} \mathrm{ml} \mathrm{m}^{-1}$. For strains carrying lac $Z$ fusions, X-Gal was included in solid medium at $40 \mu \mathrm{g} \mathrm{ml}^{-1}$. CAS plates used to screen $B$. cenocepacia mutants for siderophore production were made as described by Agnoli et al. (2006). For assaying enterobactin production by E. coli strains, CAS agar was made by adding $10 \mathrm{ml}$ CAS reagent (Schwyn \& Neilands, 1987) to $90 \mathrm{ml} \mathrm{M9}$ salts agar supplemented with glucose $(0.2 \%)$, casamino acids $(0.2 \%)$, leucine $\left(20 \mu \mathrm{g} \mathrm{ml}^{-1}\right)$, proline $\left(20 \mu \mathrm{g} \mathrm{ml}^{-1}\right)$, tryptophan $\left(10 \mu \mathrm{g} \mathrm{ml}^{-1}\right)$ and thiamine $\left(5 \mu \mathrm{g} \mathrm{ml} \mathrm{m}^{-1}\right)$. EDDHA plates were made by adding ethylenediaminedi( $o$-hydroxyphenylacetic) acid (EDDHA) to M9CAA agar at a final concentration of $35 \mu \mathrm{g} \mathrm{ml}{ }^{-1}$.
For measurement of the effect of iron availability on the bacterial growth rate, $B$. cenocepacia strains were grown to stationary phase at $37{ }^{\circ} \mathrm{C}$ (i.e. $\sim 20 \mathrm{~h}$ ) in M9-CAA medium $\left(25 \mu \mathrm{g} \mathrm{ml}{ }^{-1}\right.$ trimethoprim was included when pAHA14 derivatives were employed). Cells from these cultures were inoculated at 100-fold dilution into $50 \mathrm{ml}$ fresh medium containing either $2,2^{\prime}$-dipyridyl $(100 \mu \mathrm{M})$ to generate ironstarvation conditions or $50 \mu \mathrm{M}$ ferric chloride for iron-replete conditions, and were grown in flasks at $37{ }^{\circ} \mathrm{C}$ with vigorous shaking. For $\beta$-galactosidase assays, B. cenocepacia strains were grown to stationary phase $(\sim 20 \mathrm{~h})$ at $37^{\circ} \mathrm{C}$ in the same medium used to culture the cells for the assay, and were diluted 100-fold into $5 \mathrm{ml}$ of this medium. To determine the effect of iron availability on gene expression, this medium was the same as that used for growth rate determination.

Plasmid and transposon construction. All plasmids and transposons used are shown in Table 1. Recombinant DNA techniques were performed essentially as described in Sambrook et al. (1989). Construction of pUC18NotlacZYA and its progenitor, pRW500, is 
described in the Supplementary Material and in Supplementary Figs S1 and S2). To construct mini-Tn5CmlacZYA and mini-Tn5TplacZYA, the $5.89 \mathrm{~kb}$ NotI lacZYA cassette of pUC18NotlacZYA was inserted into the unique NotI site located between the $\Omega$-Cm interposon and the $\mathrm{O}$ end of mini-Tn5Cm, and between the $d f r(\mathrm{Tp})$ cassette and the $\mathrm{O}$ end of mini- $\mathrm{Tn} 5 \mathrm{Tp}$, and derivatives in which the $\mathrm{N}$-terminal coding region of the lacZ gene was positioned adjacent to the $\mathrm{O}$ end of the minitransposon were selected.

pAHA14 is identical to pBBRTp (DeShazer \& Woods, 1996), and was constructed by transferring the $d f r B 2\left(\mathrm{Tp}^{\mathrm{R}}\right.$; trimethoprim-resistance) cassette (which includes the $d f r B 2$ promoter) from $\mathrm{p} 34 \mathrm{E}-\mathrm{Tp}$ into the EcoRI site located within the cat gene of pBBR1MCS. $d f r B 2$ is inserted in the opposite orientation to the cat gene. pAHA14-pobA was constructed by amplifying the pobA gene from B. cenocepacia $715 \mathrm{j}$ genomic DNA with $P f u$ Turbo DNA polymerase (Stratagene) in the presence of DMSO (5\%) using primers pobAfor (5'-GCGCAAGCTTGTAACGATCGATTAACATCGGACGT-3') and pobArev (5'-GCGCGGATCCGACAAATGGTTCATGAAGCCG-3') (restriction sites underlined), and cloning the resultant product between the HindIII and BamHI sites of pAHA14. The pobAfor primer contained a stop codon (bold type) to ensure no translational readthrough of vector-derived lac $Z$ mRNA into pobA sequences. pAHA14-entD was made by transferring the $X b a \mathrm{I}-$ NotI fragment harbouring entD from pET28b-entD into the multiple cloning site (MCS) of pAHA14. pAHA14-sfp was constructed in two steps by first transferring the EcoRI-PstI fragment containing sfp from pUC8-sfp to the pBBR1MCS MCS, and then transferring the XhoI-BamHI fragment containing sfp from the resultant plasmid, pBBR1MCS-sfp, to the pAHA14 MCS.

Plasmid transfer by conjugation and transposon mutagenesis. pUTmini-Tn5CmlacZYA was introduced into B. cenocepacia $715 \mathrm{j}$ by conjugal transfer using the E. coli donor strain BW19851, as described elsewhere (Herrero et al., 1990; de Lorenzo \& Timmis, 1994), and transposon mutants were selected on CAS agar containing chloramphenicol $\left(50 \mu \mathrm{g} \mathrm{ml}^{-1}\right)$. Kanamycin $\left(25 \mu \mathrm{g} \mathrm{ml}^{-1}\right)$ was also added to counterselect the donor. Following incubation at $37^{\circ} \mathrm{C}$ for 2 days, siderophore-deficient mutants were identified by the decreased size of the orange zone around the colony. E. coli donor strain SM10( $\lambda$ pir) was used to transfer pAHA14 derivatives to $B$. cenocepacia with selection for exconjugants performed on M9-glucose agar containing trimethoprim $\left(25 \mu \mathrm{g} \mathrm{ml}^{-1}\right)$.

Siderophore analysis. Overnight cultures of bacteria were inoculated at 1:100 dilution into $3 \mathrm{ml} \mathrm{M}$ 9-glucose (for analysis of ornibactin production) or $30 \mathrm{ml} \mathrm{M9-glucose} \mathrm{containing} 0.5 \%$ CAA (for analysis of pyochelin production) containing appropriate antibiotics, and the bacteria were grown with aeration at $37^{\circ} \mathrm{C}$ for 36-48 $\mathrm{h}$. The analysis of pyochelin (and salicylic acid) production was carried out by TLC, as previously described (Farmer \& Thomas, 2004). Under these conditions, the two naturally occurring stereoisomers of pyochelin (pyochelin I and pyochelin II) migrate as two very closely spaced yellow-green fluorescent bands midway between the origin and the solvent front, while salicylate runs as a blue fluorescent band very close to the solvent front (Rinehart et al., 1995; Farmer \& Thomas, 2004; Schlegel et al., 2004). Ornibactin production was assessed by the IEF-CAS overlay method (Koedam et al., 1994; Agnoli et al., 2006). The location of ornibactin was determined by comparing the profiles of strain Pc105, which produces ornibactin but not pyochelin, and Pc22-12, which produces neither siderophore (Darling et al., 1998).

Identification of mini-Tn5CmlacZYA insertion sites. Genomic DNA from B. cenocepacia mutants was purified using the PureGene Genomic DNA Isolation kit (Gentra Systems) as recommended by the manufacturer. Following separate overnight digestion with SacI and SacII (both of which cut mini-Tn5CmlacZYA between the lacZYA cassette and the $\Omega-\mathrm{Cm}$ interposon and, in the case of SacI, within the lacZ gene), the DNA was fractionated in a $0.8 \%$ agarose gel and transferred to a Hybond- $\mathrm{N}+$ nylon membrane (Amersham Pharmacia Biotech) by Southern blotting (Sambrook et al., 1989), after which hybridization was carried out under normal stringency conditions using mini-Tn5CmlacZYA probe DNA labelled by the ECL Direct Nucleic Acid Labelling and Detection system (Amersham Pharmacia Biotech). Genomic fragments corresponding in size to the fragments hybridizing to the probe were eluted from gel slices, ligated to plasmid pUC19 (SacI fragments) or pBBR1MCS-4 (SacII fragments), and used to transform E. coli JM83 or MC1061 to ampicillin resistance with concomitant selection for chloramphenicol resistance or screening for a $\mathrm{Lac}^{+}$phenotype on medium containing $\mathrm{X}$-Gal, respectively. The nucleotide sequence of the cloned genomic DNA was subsequently determined.

$\boldsymbol{\beta}$-Galactosidase assays. B. cenocepacia cultures were grown in triplicate to $\mathrm{OD}_{600} 0.4-0.8$ as described above, whereupon the cells were chilled on ice for at least $15 \mathrm{~min}$. Duplicate assays were performed at $30{ }^{\circ} \mathrm{C}$ on $25-200 \mu \mathrm{l}$ cells from each culture in a total volume of $1 \mathrm{ml}$ following permeabilization of the cells with chloroform/SDS (Miller, 1972).

\section{RESULTS}

\section{Construction of new reporter transposons for use in Burkholderia}

Tn5 derivatives have been shown to be useful for genetic analysis of members of the genus Burkholderia (Dennis \& Zylstra, 1998; Sokol et al., 1999; Farmer \& Thomas, 2004; Agnoli et al., 2006). To increase the versatility of these transposons, we inserted a promoterless lac cassette into the unique NotI site of mini-Tn5Cm and mini-Tn5Tp, thereby allowing lac $Z$ to serve as a reporter of transcription originating in genomic DNA flanking the $\mathrm{O}$ end of the integrated transposon. The resultant transposons were named mini-Tn5CmlacZYA and mini-Tn5TplacZYA (Fig. 1), and are contained in the mobilizable suicide plasmid pUT (de Lorenzo \& Timmis, 1994). The transferred lac $Z$ gene is devoid of the segments of the $E$. coli $\operatorname{trp} B$ and $\operatorname{trp} A$ genes that are fused to the $5^{\prime}$ end of lac $Z$ in many transcriptional reporter plasmids and transposons (see Supplementary Material). To prevent the formation of translational fusions, translation termination codons are present in all three reading frames upstream of the lac $Z$ Shine-Dalgarno sequence. The nucleotide sequence of the region upstream of the $l a c Z$ translation initiation codon is shown in Supplementary Fig. S2.

\section{Isolation of $B$. cenocepacia mutants in which production of both ornibactin and pyochelin is decreased or abolished}

B. cenocepacia strain $715 \mathrm{j}$ produces the siderophores ornibactin and pyochelin (Darling et al., 1998; Visser et al., 2004; Farmer \& Thomas, 2004; Agnoli et al., 2006). To test the effectiveness of mini-Tn5CmlacZYA, it was used to generate mutants of $715 j$ that were deficient in production of both siderophores ( $\mathrm{Orb}^{-} \mathrm{Pch}^{-}$phenotype). 

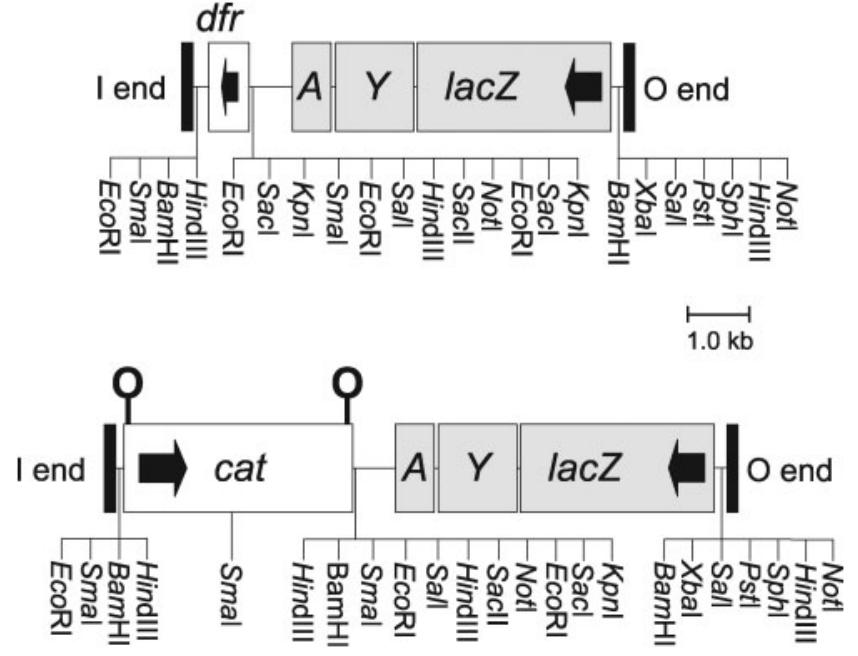

Fig. 1. Schematic representation of mini-Tn5TplacZYA and miniTn5CmlacZYA. The Notl lacZYA cassette introduced into miniTn5Tp and mini-Tn5Cm contains the lacZ, lacY and lacA genes (shown with grey shading). Preceding the lac $Z$ translation initiation codon is a $200 \mathrm{bp}$ leader region containing an RNase III processing site and translation termination codons in all three reading frames. Also present on the cassette are $600 \mathrm{bp}$ of DNA that is located downstream of the lac $A$ translation stop codon on the $E$. coli chromosome. The origin of the lacZYA cassette is described in the Supplementary Material. Transcription termination signals located at each end of the $\Omega$-Cm interposon used to construct mini-Tn5Cm are represented by lollipop motifs. Note that the orientation of the cat gene in mini- $\mathrm{Tn} 5 \mathrm{Cm}$ has been confirmed by DNA sequencing, and is different from that shown elsewhere (Fellay et al., 1987; de Lorenzo et al., 1990; de Lorenzo \& Timmis, 1994). The $19 \mathrm{bp} O$ and I end repeat sequences flanking each transposon are indicated by vertical black bars. Sites for commonly used restriction enzymes are shown (note that single Sacl sites are also located in lac $Z$ and $d f r$ ).

In two separate mutagenesis experiments, siderophoredeficient mutants were identified on CAS agar by the absence of an orange halo surrounding the colony or the presence of a halo of decreased size. Only one mutant was identified (AHA27) in which the production of a halo was completely abolished, although several mutants were identified which generated a very small halo. As expected, analysis of individual siderophore production showed that AHA27 failed to produce either ornibactin or pyochelin when growing in liquid culture under iron-limiting conditions (Fig. 2a, b). Production of the pyochelin precursor salicylic acid by this mutant was reduced although not abolished. Of the mutants that produced a very small orange zone around the growth, IW10 produced trace amounts of pyochelin in liquid culture, whereas production of salicylate and ornibactin was not significantly affected (Fig. 2c, d). The phenotypes of AHA27 and IW10 in the CAS plate assay are shown in Fig. 2(e). The absence of an orange zone around the growth of AHA27 on CAS plates confirms a previous observation that salicylate is not active as a siderophore in the CAS assay, although it has been proposed as a siderophore for B. cenocepacia (Sokol et al., 1992, 1999; Visca et al., 1993).

\section{Genomic loci of transposon insertions in pyochelin-deficient mutants}

Genomic DNA isolated from the two pyochelin-deficient mutants was digested with the restriction enzyme SacII and probed with mini-Tn5CmlacZYA DNA following Southern blotting. The probed digestions revealed that a single transposon insertion had occurred in each case (results not shown). Nucleotide sequence analysis of the DNA flanking the transposons in AHA27 and IW10 revealed that in both mutants, the transposon had integrated into a 251 codon ORF, which we have named pobA (pyochelin and ornibactin biosynthesis) (Fig. 3). This corresponds to BCAL2248 in the recently published genome sequence of $B$. cenocepacia strain J2315 (Holden et al., 2009), and the protein product of the $715 \mathrm{j} \mathrm{pobA}$ gene differed at only one amino acid position from the predicted product of BCAL2248 (the substitution of alanine for valine at amino acid position 215). In IW10, the lacZ gene was inserted in the same orientation as pobA, whereas in AHA27 the lac $Z$ was inserted in the reverse orientation (Fig. 3).

The $p o b A$ gene encodes a polypeptide that exhibits strong similarity to bacterial PPTases required for activating ArCP and PCP domains of NRPSs. The strongest matches (38\% identity over the matching region) to proteins outside the genus Burkholderia were to a putative Sfp-type PPTase proposed to be involved in the biosynthesis of the lipopeptide antibiotic iturin A by Synechocystis spp. and to the HetI protein, a PPTase which has been proposed to be required for biosynthesis of a secondary metabolite involved in heterocyst formation by Nostoc spp. (Black \& Wolk, 1994; Kaneko et al., 1996; Lambalot et al., 1996). Both organisms are members of the Cyanobacteria. The amino acid sequence of the predicted PobA polypeptide was also similar to those of characterized Sfp-type PPTases, including the Streptomyces venezuelae jadM gene product, required for biosynthesis of the antibiotic jadomycin, the Mycobacterium tuberculosis $p p t T$ gene product, required for biosynthesis of the siderophore mycobactin, the E. coli PPTase EntD, and Sfp itself (Lambalot et al., 1996; Quadri et al., 1998a, b; Wang et al., 2001). The amino acid sequence alignment showed that PobA contains the signature sequence that characterizes both Sfp- and AcpS-type PPTases, and also revealed an additional motif, 'ppt-S', that is conserved in all Sfp-type PPTases (see Discussion). Furthermore, the alignment also showed that the Sfp subclass of PPTases falls into two conserved subgroups, I and II.

Consistent with the inability of AHA27 to produce siderophores, mini-Tn5CmlacZYA had inserted between codons 98 and 99 of pobA in this mutant. However, in IW10, the transposon had inserted between the first and second bases of the predicted initiation codon for pobA 


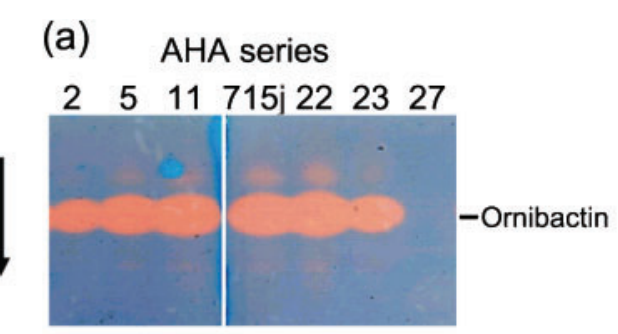

(b) AHA series

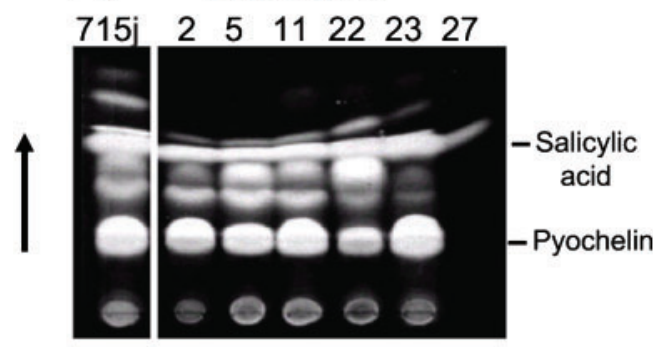

(c) IW series

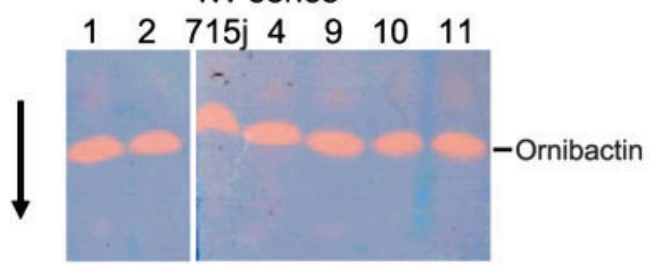

(d)

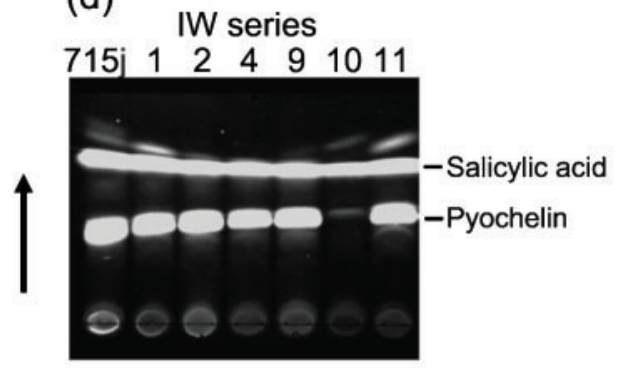

(e) $715 j$

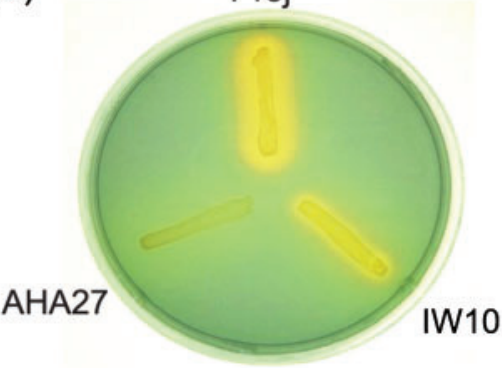

translation. As the terminal base of the transposon I end is a $G$ residue, transposon insertion resulted in replacement of the native ATG codon by an alternative initiation codon (GTG), which may give rise to low levels of PobA synthesis in this mutant. A decreased level of PobA may have led to the observed negative effect on pyochelin biosynthesis if the
Fig. 2. Analysis of siderophore production by $B$. cenocepacia mutants exhibiting decreased halo sizes on CAS agar plates. Ornibactin production $(\mathrm{a}, \mathrm{c})$ and pyochelin production $(\mathrm{b}, \mathrm{d})$ by the AHA and IW series of mutants (indicated accordingly) was assessed by IEF and TLC analysis, respectively, of cell supernatants from cultures grown to stationary phase in M9-CAA. The locations of siderophores and the pyochelin precursor salicylic acid are indicated. Vertical arrows indicate the direction of sample migration. The phenotypes of the pobA mutants AHA27 and IW10 on CAS agar are shown in (e).

enzyme possesses an intrinsically low phosphopantetheinylation activity towards one or more of the ArCP or PCP domains in PchE or PchF.

\section{Effect of pobA disruption on growth under iron- limiting conditions}

To examine the effect of disruption of $p o b A$ on growth of $B$. cenocepacia, the ability of both mutants to grow under conditions of iron limitation was examined. On agar containing the iron(III) chelator EDDHA, IW10 exhibited the same colony-forming ability as its parent strain, $715 \mathrm{j}$, whereas growth of AHA27 was inhibited on this medium. In contrast, on standard minimal salts agar (without addition of iron) the two mutant strains formed colonies with equal efficiency (results not shown). Growth of the mutants was also monitored in liquid culture under ironreplete and iron-limiting conditions. Under iron-replete conditions, both mutants grew at a similar rate to the parent strain (Fig. 4a). In the presence of the iron chelator $2,2^{\prime}$-dipyridyl, the growth of the wild-type strain and IW10 was similar to that of iron-fed cells during early to mid exponential growth, but their growth rates became retarded relative to iron-fed cells during the mid to late exponential phase (i.e. at $\mathrm{OD}_{600} \sim 0.5$ ). In contrast, growth of the AHA27 mutant was almost completely abolished under iron-limiting conditions (Fig. 4a).

\section{Complementation of the pobA mutant by characterized PPTase genes}

To confirm that the observed phenotypes of AHA27 and IW10 are a direct result of disruption of the pobA reading frame, a complementation test was performed using pAHA14-pobA, in which the pobA gene is placed under the control of the lac promoter. Introduction of this plasmid into the $p o b A$ mutants resulted in a wild-type siderophore phenotype in the CAS plate assay (Fig. 5a; result for IW10 not shown). Analysis of individual siderophores produced by the complemented mutants showed that the wild-type copy of pobA restores normal production of pyochelin to mutant IW10, and of both pyochelin and ornibactin to AHA27 (Fig. 5b and results not shown). The results also showed that pAHA14-pobA, but not pAHA14, conferred on AHA27 the ability to grow 


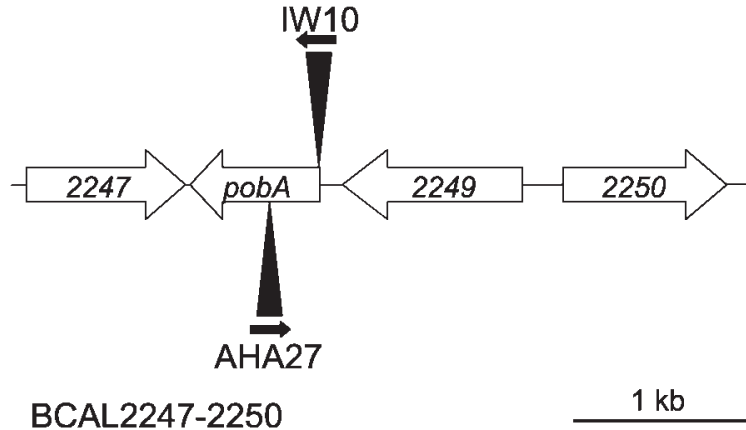

Fig. 3. Genomic location of transposon insertions in the $B$. cenocepacia siderophore-deficient mutants AHA27 and IW10. A region of the large chromosome (chromosome 1) is shown that corresponds to the gene loci BCAL2247-2250 in strain J2315 (Holden et al., 2009). The location of the mini-Tn5CmlacZYA insertions in pobA (BCAL2248) and the direction of transcription of the inserted lacZ gene are indicated. BCAL2249 encodes a putative hydrolase with an $\alpha / \beta$ fold. This has been annotated as a serine peptidase (Holden et al., 2009). BCAL2247 encodes a predicted periplasmic binding protein component of an $A B C$ solute transporter, possibly involved in uptake of glutamate or aspartate.

at the wild-type rate under iron-limiting conditions (Fig. 4b).

To test the hypothesis that pobA encodes a PPTase, we carried out a complementation test with two well-studied PPTase genes: the E. coli entD gene, required for biosynthesis of the siderophore enterobactin, and the Bacillus subtilis sfp gene, required for biosynthesis of surfactin. Both entD and $s f p$ (without their cognate promoters) were subcloned into pAHA14 under the control of the lac promoter, and the resultant plasmids were introduced into AHA27 and IW10. Fig. 5(a, b) shows that both PPTase genes were able to restore the wild-type phenotype to AHA27 in the CAS plate assay as well as normal production of pyochelin.

\section{Complementation of an $E$. coli entD mutant by pobA}

The CAS plate assay can be used to distinguish between enterobactin-producing and non-producing strains (Schwyn \& Neilands, 1987). Thus, the E. coli entD mutant AN90, which fails to biosynthesize enterobactin, gave a negative result in this assay, whereas the ent $D^{+} E$. coli strain JM83 gave a positive result (Fig. 5c). As expected, expression of entD in AN90 in trans resulted in the restoration of siderophore production, yielding a phenotype identical to that of JM83. The same result was observed for the heterologous PPTase gene $s f p$, as reported elsewhere (Grossman et al., 1993). Moreover, pobA was also able to substitute for entD in the complementation assay (Fig. 5c). This observation is consistent with the (a)

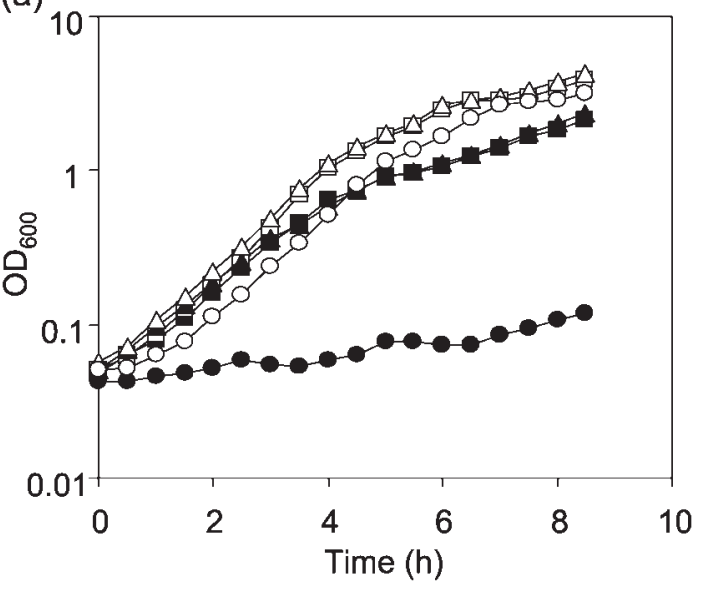

(b)

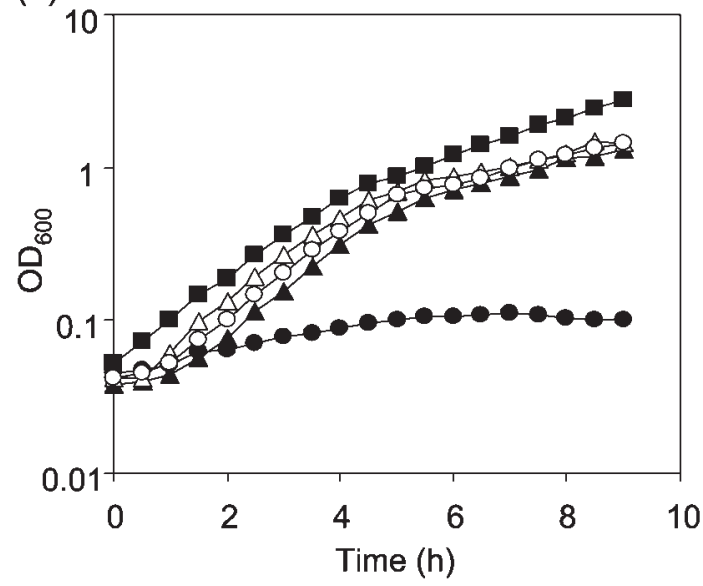

Fig. 4. Effect of decreased iron availability on growth of $B$. cenocepacia pobA mutants in the absence/presence of wild-type pobA provided in trans. (a) Effect of decreased iron availablility on pobA mutants. Bacteria were grown at $37{ }^{\circ} \mathrm{C}$ in M9-CAA medium in the presence of $2,2^{\prime}$-dipyridyl '(-Fe)' or ferric chloride '(+Fe)'. 口, 715j(-Fe); •, AHA27(-Fe); $\mathbf{\Delta}, \mathrm{IW} 10(-\mathrm{Fe}) ; \square, 715 \mathrm{j}(+\mathrm{Fe})$; $\bigcirc$, $\mathrm{AHA} 27(+\mathrm{Fe}) ; \triangle$, IW10 (+Fe). (b) Complementation of AHA27 by pobA in trans. Bacteria were grown as described for (a) and all cultures contained dipyridyl in the medium. $\mathbf{0}, 715 \mathrm{j}(\mathrm{pAHA} 14)$; AHA27(pAHA14); $\boldsymbol{\Delta}, \quad$ IW10(pAHA14); O, AHA27(pAHA14pobA); $\triangle$, IW10(pAHA14-pobA).

results of the $p o b A$ mutant complementation assay, and confirms that pobA encodes an Sfp-type PPTase.

\section{Effect of iron limitation on expression of the pobA gene}

As pobA is required for growth under iron-starvation conditions, mutant IW10 was used to monitor the regulation of $p o b A$ in response to iron. Due to the requirement for a fully functional pobA gene to ensure efficient siderophore production under iron-starvation conditions, $\beta$-galactosidase assays were carried out using a strain harbouring pAHA14-pobA. The results showed 
(a)

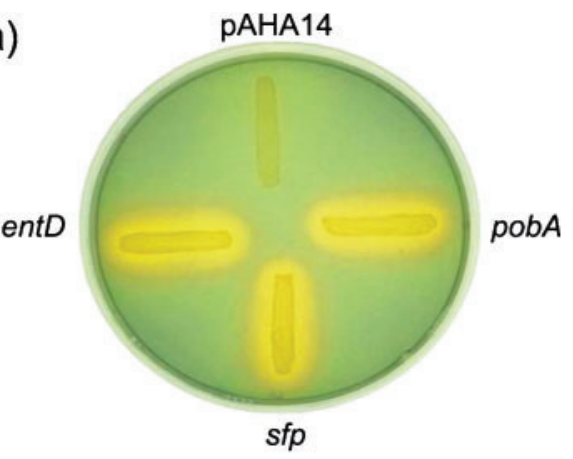

(b)

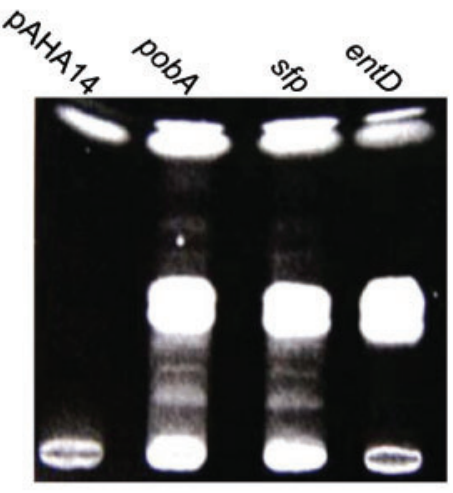

(c)

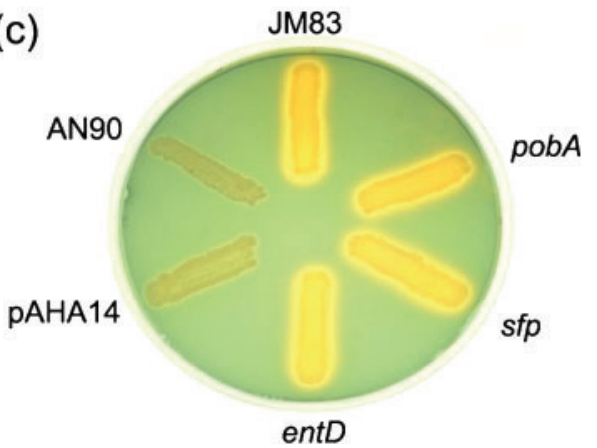

Fig. 5. Complementation of PPTase mutants by pobA orthologues. pAHA14 and derivatives containing pobA, entD or sfp were introduced into $\mathrm{AHA} 27$ by conjugation or into $E$. coli $\mathrm{AN} 90$ by transformation, and siderophore production was assayed. The presence of particular pAHA14 derivatives is indicated by the PPTase gene that they carry. (a) CAS plate assay of AHA27 containing pobA orthologues. (b) Pyochelin production by AHA27 containing $p o b A$ orthologues. Following growth under irondepleted conditions, pyochelin production was assessed by TLC. (c) CAS plate assay of AN90 containing pobA orthologues. JM83 was included as a positive control for enterobactin production by $E$. coli.

that in cells containing multicopy pobA, iron had very little effect on $p o b A$ transcription. In the absence of the $p o b A$ plasmid, transcription of the $p o b A$ gene in iron-starved cells increased significantly relative to that in the $p o b A^{+}$

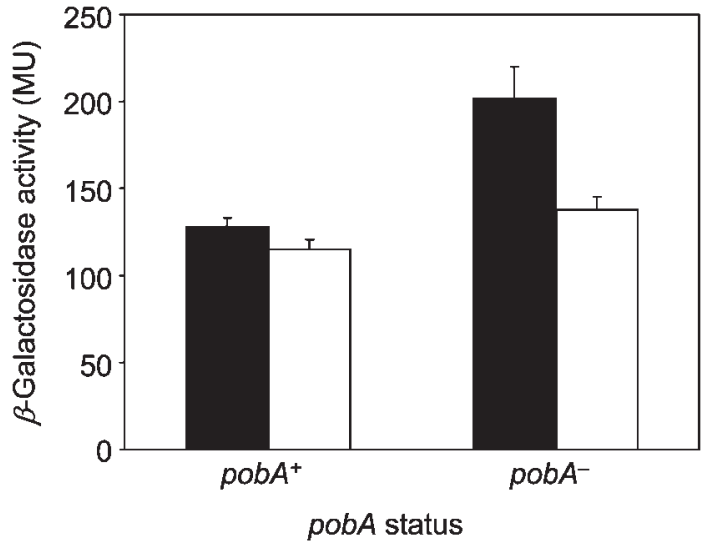

Fig. 6. Effect of iron availability on transcription of pobA. $B$. cenocepacia strain IW10 containing pAHA14 (status pobA ${ }^{+}$) or pAHA14-pobA (status $p o b A^{-}$) was grown to mid exponential phase at $37{ }^{\circ} \mathrm{C}$ in M9-CAA under iron-limiting conditions (black bars) and iron-sufficient conditions (white bars), whereupon $\beta$ galactosidase assays were performed. Values, presented in Miller units (MU), are the means (with SD) of at least three assays.

strain growing under the same conditions ( $57 \%$ increase), and this was repressed by iron to a level similar to that measured in $p o b A^{+}$cells growing under ironreplete conditions (Fig. 6).

\section{DISCUSSION}

In this study we have demonstrated that a single Sfp-type PPTase, PobA, is required for ornibactin and pyochelin biosynthesis in $B$. cenocepacia. The function of PobA is almost certainly to activate the OrbI, OrbJ, PchE and PchF NRPSs that participate in the biosynthesis of these siderophores. In contrast to the Sfp-type PPTase of $P$. aeruginosa (PcpS), which activates NRPSs involved in pyochelin and pyoverdine biosynthesis and also serves as the ACPS, PobA is not essential for growth of $B$. cenocepacia under ironsuffiicient conditions. This suggests that an ACPS, or an additional Sfp-type PPTase with broad substrate specificity, is encoded by the $B$. cenocepacia genome. TBLASTN analysis of the genomes of B. cenocepacia strains HI2424 and J2315 reveals that they encode an ACPS [in fact, chromosome 1 of strain $\mathrm{J} 2315$ contains a duplication of $57 \mathrm{~kb}$ which gives rise to two identical copies of an acpS orthologue: BCAL1009 and BCAL2861 (Holden et al., 2009; Sousa et al., 2008)]. Furthermore, there are no additional Sfp-type PPTases encoded by the genome of strain J2315. Therefore, the nonlethality of the pobA null mutation is almost certainly due to the presence of an ACPS in B. cenocepacia. Although it is possible that PobA also serves as an ACPS, we have not explored whether, in the absence of an ACPS, PobA is able to support the growth of $B$. cenocepacia.

ACPS and Sfp-type PPTases share a common signature sequence (Lambalot et al., 1996; Walsh et al., 1997; Quadri 
et al., 1998b). With the huge increase in the number of bacterial genomic sequences now available, search and alignment tools have allowed us to make comparisons between a large number of Sfp-type PPTases and ACPSs, representing most of the major bacterial taxa. As outlined below, this analysis supports the idea that the subfamily of bacterial Sfp-type PPTases should be divided into two distinct groups (Copp \& Neilan, 2006), one of which shares a more extended region of homology with the ACPSs.

(i) Our analysis confirms that the originally proposed signature sequence for PPTases, composed of two conserved motifs $\left[(\mathrm{V} / \mathrm{I}) \mathrm{G}(\mathrm{V} / \mathrm{I}) \mathrm{D}(\mathrm{x})_{40-45}(\mathrm{~F} / \mathrm{W})(\mathrm{S} / \mathrm{C} / \mathrm{T}) \mathrm{xKE}\right.$ (A/S)hhK, where $\mathrm{x}$ is any amino acid and $\mathrm{h}$ is an amino acid with a hydrophobic sidechain], generally holds true (Lambalot et al., 1996; Walsh et al., 1997). However, we have extended and refined the signature sequence to (I/ $\mathrm{V} / \mathrm{L}) \mathrm{G}(\mathrm{I} / \mathrm{V} / \mathrm{L} / \mathrm{T}) \mathrm{D}(\mathrm{I} / \mathrm{V} / \mathrm{L} / \mathrm{A})(\mathrm{x})_{\mathrm{n}}(\mathrm{F} / \mathrm{W})(\mathrm{A} / \mathrm{S} / \mathrm{T} / \mathrm{C}) \mathrm{xKE}(\mathrm{S} / \mathrm{A}) \mathrm{h}$ $(\mathrm{h} / \mathrm{S}) \mathrm{K}(\mathrm{A} / \mathrm{G})$ for bacterial PPTases (where $\mathrm{n}$ is $42-48$ for ACPSs and 38-41 for the Sfp subfamily of PPTases). We refer to the two conserved motifs as ppt-1 and ppt-3
(Fig. 7). The previously identified invariant glutamate, corresponding to E127 in Sfp (Reuter et al., 1999), forms part of a less well-conserved (L/I/V/M/F)(x) $3(\mathrm{~V} / \mathrm{I} / \mathrm{Y} /$ $\mathrm{F}) \mathrm{h}(\mathrm{x})_{3} \mathrm{E}(\mathrm{x})_{3} \mathrm{~h}$ motif (ppt-2) located between ppt-1 and ppt-3.

(ii) Located 12-23 amino acids N-terminal to the PPTase signature sequence is a tetrapeptide motif $(\mathrm{L} / \mathrm{I} / \mathrm{V} / \mathrm{M})(\mathrm{S} /$ $\mathrm{T}) \mathrm{H}(\mathrm{S} / \mathrm{T} / \mathrm{C} / \mathrm{A})$, which is conserved among all the bacterial Sfp-type PPTases (Fig. 7). As this motif (ppt-S) resides in a region of the Sfp-type PPTases that is not present in ACPSs, it can be considered diagnostic for this class of PPTase. Sanchez et al. (2001) identified a motif they termed P1 [PxWPxG(x) ${ }_{2}$ GS(M/L)THCxGY] in a subset of Sfp-type PPTases encoded by members of the actinomycetes, within which ppt-S is present (underlined). However, P1 is not conserved among all the bacterial Sfp-type PPTases [see (iii) below]. The P1 motif has been referred to as 'Motif 1' by Copp \& Neilan (2006), who also recognized that it is not conserved in all Sfp-type PPTases. Bacterial Sfp-type PPTases are also characterized by a

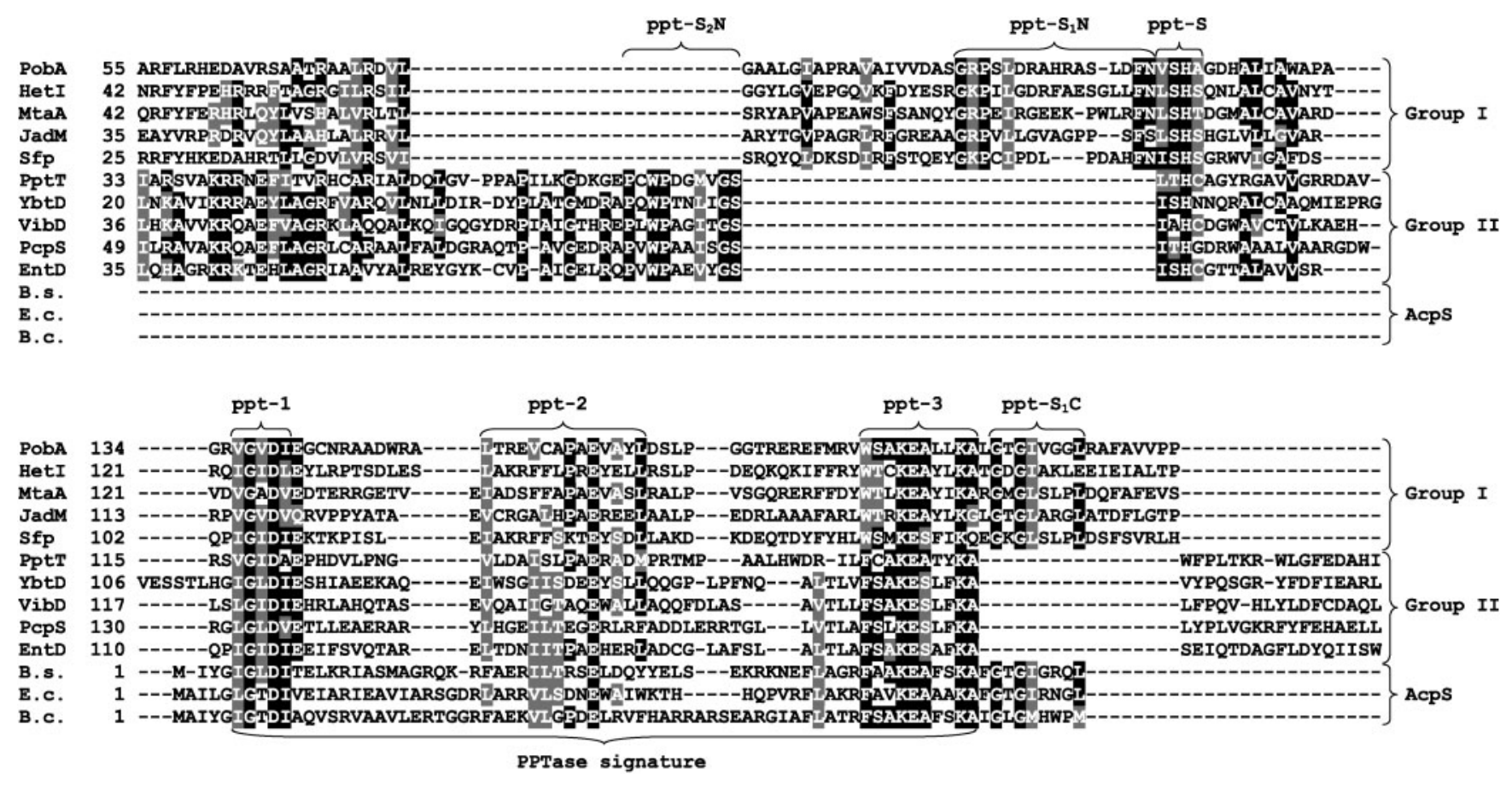

Fig. 7. Alignment of the central conserved region of bacterial Sfp-type PPTases with the N-terminal region of AcpS-type PPTases. A selection of both types of PPTase was aligned using the CLUSTAL W program (Thompson et al., 1994) and highlighted using the Boxshade program accessed through the Swiss Institute of Bioinformatics website (http://www.ch. embnet.org/index.html). Amino acid residues that are identical at the corresponding position in $\geqslant 50 \%$ of sequences are shown in white type with a black background. Similar amino acids are shown in white type with a grey background. The alignment was then gapped manually in order to highlight the motifs characteristic of the Group I and Group II Sfp-type PPTases. Only a representative number of the total residues aligned is shown. Consensus sequences of the conserved motifs described in the text were derived from a more comprehensive alignment than is shown here. The PPTases shown, in descending order, are $B$. cenocepacia PobA (ABD60228), Nostoc sp. Hetl (AAA22003), Stigmatella aurantica MtaA (AAF19809), S. venezuelae JadM (AAF34678), Bacillus subtilis Sfp (CAA44858), M. tuberculosis PptT (CAA15589), Yersinia pestis YbtD (NP_669888), Vibrio cholerae VibD (NP_230429), P. aeruginosa PcpS (NP_249856) and E. coli EntD (NP_415115), and the AcpS-type PPTases of Bacillus subtilis (B.s.; NP_388343), E. coli (E.c.; NP_417058) and B. cenocepacia (B.c.; CAR51316). 
highly conserved glutamate or glutamine residue located immediately C-terminal to ppt-1. In the crystal structure of Sfp, the carboxyl group of the glutamate residue at this position provides a ligand for a metal ion that is probably magnesium (Reuter et al., 1999).

(iii) Amino acid sequences located N-terminal to ppt-S and C-terminal to ppt-3 highlight a clear division within the bacterial Sfp-type PPTases. Highly conserved amino acid sequence motifs within these regions allow the assignment of an Sfp-type PPTase to one or other 'group'. For example, Group I Sfp-type PPTases, which include PobA and Sfp, are characterized by the sequence $\mathrm{G}(\mathrm{R} / \mathrm{K}) \mathrm{Px}(\mathrm{L} / \mathrm{I} /$ $\mathrm{V})-(\mathrm{x})_{7-13}-\mathrm{FN}$ (termed ppt- $\mathrm{S}_{1} \mathrm{~N}$ ) immediately preceding ppt-S, and $\mathrm{GxG}(\mathrm{L} / \mathrm{I} / \mathrm{F})(\mathrm{x})_{3}(\mathrm{~L} / \mathrm{I} / \mathrm{M} / \mathrm{V})$ (ppt-S $\left.\mathrm{C}_{1}\right)$ immediately following ppt-3. The latter motif is also present at the corresponding position in ACPSs, therefore effectively extending the PPTase signature region for ACPSs and Group I Sfp-type PPTases (Fig. 7). On the other hand, Group II Sfp-type PPTases, which include EntD and PcpS, are characterized by the presence of the sequence PxWPxxhxGS (ppt- $\mathrm{S}_{2} \mathrm{~N}$ ) immediately preceding ppt-S, and the tripeptide $\mathrm{x}(\mathrm{Y} / \mathrm{F}) \mathrm{P}\left(\mathrm{ppt}-\mathrm{S}_{2} \mathrm{C}\right)$ is generally present C-terminal to ppt-3 (although the latter motif is not conserved strongly enough to be diagnostic of Group II Sfp-type PPTases). The closely related Sfp-type PPTases analysed by Sanchez et al. (2001) fall within Group II, and hence all contain ppt- $\mathrm{S}_{2} \mathrm{~N}$ fused to S-ppt, giving rise to the proposal of the P1 motif. However, the P1 motif is not present in Group I Sfp-type PPTases.

The Sfp-type PPTase dichotomy may also be discerned by reference to amino acid residues within and adjacent to the ppt-3 motif. Thus, the first residue of ppt-3 is always tryptophan (W) for Group I Sfp-type PPTases, whereas a phenylalanine $(\mathrm{F})$ is always present at this position in Group II members (and ACPSs). This difference has been employed to similarly subdivide the Sfp-type PPTases based on whether they contain the WxxKEA or FxxKES motif in ppt-3 (Copp \& Neilan, 2006). However, a serine residue may be found at the position occupied by an alanine in most members of the W/KEA subfamily (Group $\mathrm{I})$, such as in Sfp, and the opposite is also true for PptT. We also note that position 8 of ppt-3 is always a phenylalanine or a tyrosine (Y) in the Group II Sfp-type PPTases, whereas amino acids with aromatic side chains are not present at this position in members of Group I (and ACPSs). A phenylalanine is usually located at the fourth position $\mathrm{N}$ terminal to ppt-3 in Group I members (Fig. 7).

The dichotomy within the Sfp-type PPTases is highlighted in the phylogenetic tree shown in Fig. 8. Note that Group I and Group II Sfp-type PPTases are not restricted to particular bacterial phyla or classes. As pointed out before, members of the same genera may encode phylogenetically distant PPTases (Copp \& Neilan, 2006). Specifically, JadM, a Group I PPTase, is found in S. venezuelae, while NysF and PptA are Group II PPTases produced by Streptomyces noursei and Streptomyces verticillus, respectively. One
GROUP II

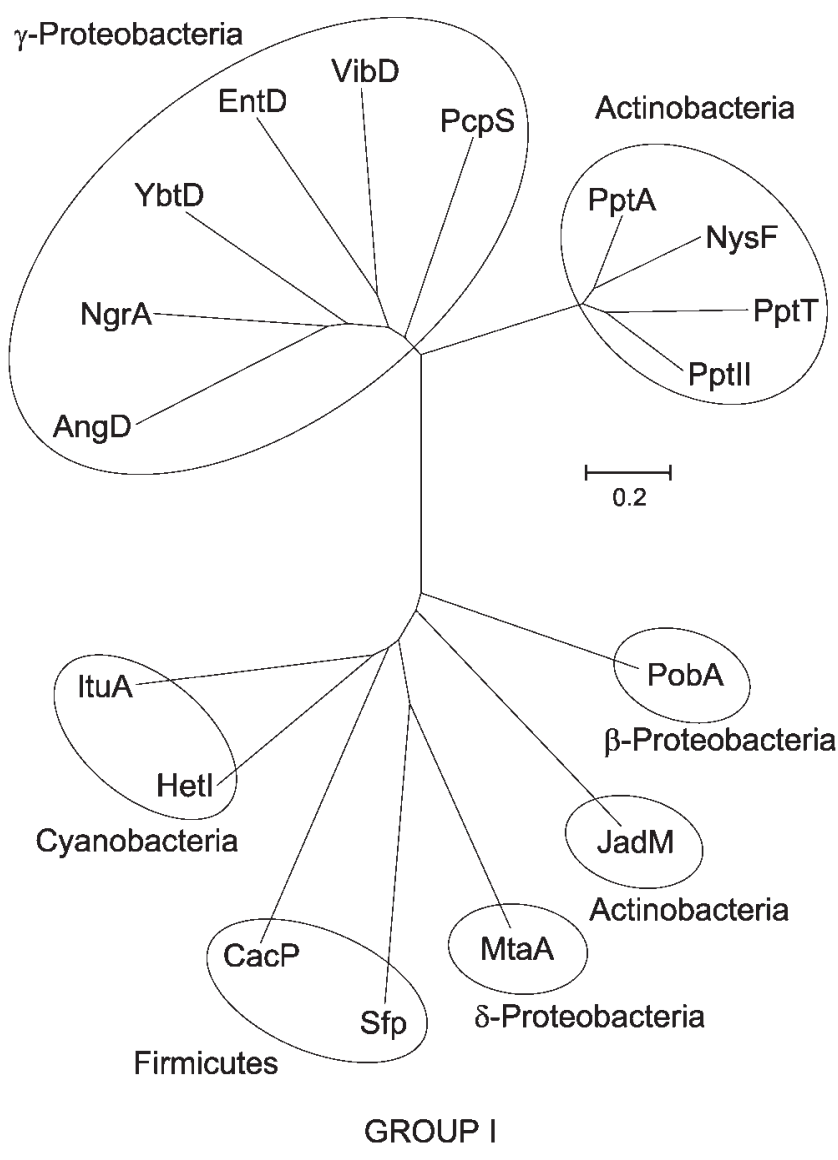

Fig. 8. Dendrogram showing the relationships among the bacterial Sfp-type PPTases. Protein sequences were retrieved from GenBank and aligned using CLUSTAL W accessed through the program MEGA 3.1 (http://www.megasoftware.net) (Kumar et al., 2004) using the default parameters. The phylogenetic tree was constructed by the neighbour-joining and minimal evolution methods within the same program. PPTases from bacterial species within the same phylum (or same class in the case of the Proteobacteriaceae) are enclosed in ellipses. The scale bar represents the number of amino acid substitutions per site. Accession numbers are as listed in the legend to Fig. 7, with the addition of Listonella anguillarum AngD (NP_943585), Photorhabdus luminescens NgrA (AAK16071), S. verticillus PptA (AAG43513), S. noursei NysF (AAF71762), Saccharopolyspora erythraea Pptll (ZP_06564430), Clostridium acetobutylicum CacP (AAK79965) and Synechocystis sp. ItuA (NP_442256).

possibility is that the division within the Sfp-type PPTases reflects a functional difference. However, although EntD and PcpS both fall within the Group II Sfp-type PPTases, only one of them (PcpS) can substitute for AcpS (Flugel et al., 2000; Finking et al., 2002; Barekzi et al., 2004). Similarly, Sfp and PcpS are members of different PPTase groups, but both can substitute for AcpS (Fig. 7; Mootz et al., 2001). 
We have described a reporter transposon, the utility of which was tested by investigating the regulation of the pobA gene. Our results imply that in wild-type cells, the pobA gene is not subject to strong regulation by iron. This is consistent with a role for PobA in the biosynthesis of other non-ribosomally synthesized peptides that are not involved in iron acquisition. However, in a mutant lacking a fully functional Sfp-type PPTase growing in iron-poor media, pobA transcription is enhanced. The mechanism for this is not clear but there are no obvious Fur box-like sequences present upstream of pobA or BCAL2249. Moreover, the degree of iron-dependent regulation is modest compared with many other iron- or Fur-regulated genes.

In a recent assessment of the role of different potential virulence determinants of $B$. cenocepacia in a variety of animal model systems, it was shown that the ability to produce the siderophores ornibactin and pyochelin was consistently required for virulence in all the model systems tested (Uehlinger et al., 2009). Thus, PobA represents a potential target for the development of therapeutic agents to control infections by Burkholderia spp.

\section{ACKNOWLEDGEMENTS}

A. H. A. was supported by a scholarship from the University of Umm Al-Qura and administered through the Saudi Arabian Ministry of Higher Education. K. A. was supported by a UK Medical Research Council (MRC) postgraduate studentship G78/7919. We would like to thank Dr Michael Kovach (Baldwin-Wallace College, $\mathrm{OH}$ ) for plasmid pBBR1MCS-4, Dr Coni Reimmann (Université de Lausanne) for pET28b-entD, Dr Peter Zuber (Oregon Health and Science University) for pUC8-sfp and Dr Bryan Bellaire (Iowa State University) for E. coli strain AN90.

\section{REFERENCES}

Agnoli, K., Lowe, C. A., Farmer, K. L., Husnain, S. I. \& Thomas, M. S. (2006). The ornibactin biosynthesis and transport genes of Burkholderia cenocepacia are regulated by an ECF $\sigma$ factor which is a part of the Fur regulon. J Bacteriol 188, 3631-3644.

Ankenbauer, R. G., Toyokuni, T., Staley, A., Rinehart, K. L., Jr \& Cox, C. D. (1988). Synthesis and biological activity of pyochelin, a siderophore of Pseudomonas aeruginosa. J Bacteriol 170, 5344-5351.

Barekzi, N., Joshi, S., Irwin, S., Ontl, T. \& Schweizer, H. P. (2004). Genetic characterization of $p c p S$, encoding the multifunctional phosphopantetheinyl transferase of Pseudomonas aeruginosa. Microbiology 150, 795-803.

Black, T. A. \& Wolk, C. P. (1994). Analysis of a $\mathrm{Het}^{-}$mutation in Anabaena sp. strain PCC 7120 implicates a secondary metabolite in the regulation of heterocyst spacing. J Bacteriol 176, 2282-2292.

Braun, V. (2001). Iron uptake mechanisms and their regulation in pathogenic bacteria. Int J Med Microbiol 291, 67-79.

Brown, M. R. W., Anwar, H. \& Lambert, P. A. (1984). Evidence that mucoid Pseudomonas aeruginosa in the cystic fibrosis lung grows under iron-restricted conditions. FEMS Microbiol Lett 21, 113-117.

Casadaban, M. J. \& Cohen, S. N. (1980). Analysis of gene control signals by DNA fusion and cloning in E. coli. J Mol Biol 138, 179-207.
Challis, G. L. \& Naismith, J. H. (2004). Structural aspects of nonribosomal peptide biosynthesis. Curr Opin Struct Biol 14, 748-756.

Clowes, R. C. \& Hayes, W. (1968). Experiments in Microbial Genetics. Oxford: Blackwell Scientific Publications.

Coenye, T., Vandamme, P., Govan, J. R. W. \& LiPuma, J. J. (2001). Taxonomy and identification of the Burkholderia cepacia complex. J Clin Microbiol 39, 3427-3436.

Compant, S., Nowak, J., Coenye, T., Clement, C. \& Barka, E. A. (2008). Diversity and occurrence of Burkholderia spp. in the natural environment. FEMS Microbiol Rev 32, 607-626.

Copp, J. N. \& Neilan, B. A. (2006). The phosphopantetheinyl transferase superfamily: phylogenetic analysis and functional implications in cyanobacteria. Appl Environ Microbiol 72, 2298-2305.

Cox, G. B., Gibson, F., Luke, R. K. J., Newton, N. A., O’Brien, I. G. \& Rosenberg, H. (1970). Mutations affecting iron transport in Escherichia coli. J Bacteriol 104, 219-226.

Crosa, J. H. \& Walsh, C. T. (2002). Genetics and assembly line enzymology of siderophore biosynthesis in bacteria. Microbiol Mol Biol Rev 66, 223-249.

Darling, P., Chan, M., Cox, A. D. \& Sokol, P. A. (1998). Siderophore production by cystic fibrosis isolates of Burkholderia cepacia. Infect Immun 66, 874-877.

de Lorenzo, V. \& Timmis, K. N. (1994). Analysis and construction of stable phenotypes in Gram-negative bacteria with Tn5- and Tn10derived minitransposons. Methods Enzymol 235, 386-405.

de Lorenzo, V., Herrero, M., Jakubzik, U. \& Timmis, K. N. (1990). Mini-Tn 5 transposon derivatives for insertion mutagenesis, promoter probing, and chromosomal insertion of cloned DNA in Gramnegative eubacteria. J Bacteriol 172, 6568-6572.

Dennis, J. J. \& Zylstra, G. J. (1998). Plasposons: modular self-cloning minitransposon derivatives for rapid genetic analysis of Gramnegative bacterial genomes. Appl Environ Microbiol 64, 2710-2715.

DeShazer, D. \& Woods, D. E. (1996). Broad-host-range cloning and cassette vectors based on the R388 trimethoprim resistance gene. Biotechniques 20, 762-764.

Farmer, K. L. \& Thomas, M. S. (2004). Isolation and characterization of Burkholderia cenocepacia mutants deficient in pyochelin production: pyochelin biosynthesis is sensitive to sulphur availability. $J$ Bacteriol 186, 270-277.

Fellay, R., Frey, J. \& Krisch, H. (1987). Interposon mutagenesis of soil and water bacteria: a family of DNA fragments designed for in vitro insertional mutagenesis of Gram-negative bacteria. Gene 52, 147154.

Finking, R., Solsbacher, J., Konz, D., Schobert, M., Schafer, A., Jahn, D. \& Marahiel, M. A. (2002). Characterization of a new type of phosphopantetheinyl transferase for fatty acid and siderophore synthesis in Pseudomonas aeruginosa. J Biol Chem 277, 50293-50302.

Flugel, R. S., Hwangbo, Y., Lambalot, R. H., Cronan, J. E. \& Walsh, C. T. (2000). Holo-(acyl carrier protein) synthase and phosphopantetheinyl transfer in Escherichia coli. J Biol Chem 275, 959-968.

Gehring, A. M., Lambalot, R. H., Vogel, K. W., Drueckhammer, D. G. \& Walsh, C. T. (1997). Ability of Streptomyces species acyl carrier proteins and coenzyme A to serve as substrates in vitro for $E$. coli holo-ACP synthase. Chem Biol 4, 17-24.

Gray-Owen, S. D. \& Schryvers, A. B. (1996). Bacterial transferrin and lactoferrin receptors. Trends Microbiol 4, 185-191.

Grossman, T. H., Tuckman, M., Ellestad, S. \& Osburne, M. S. (1993). Isolation and characterization of Bacillus subtilis genes involved in siderophore biosynthesis: relationship between B. subtilis $s f p^{0}$ and Escherichia coli entD genes. J Bacteriol 175, 6203-6211. 
Heerklotz, H. \& Seelig, J. (2001). Detergent-like action of the antibiotic peptide surfactin on lipid membranes. Biophys J 81, 15471554 .

Herrero, M., de Lorenzo, V. \& Timmis, K. N. (1990). Transposon vectors containing non-antibiotic resistance selection markers for cloning and stable chromosomal insertion of foreign genes in Gramnegative bacteria. J Bacteriol 172, 6557-6567.

Holden, M. T. G., Seth-Smith, H. M. B., Crossman, L. C., Sebaihia, M., Bentley, S. D., Cerdeno-Tarraga, A. M., Thomson, N. R., Bason, N., Quail, M. A. \& other authors (2009). The genome of Burkholderia cenocepacia $\mathrm{J} 2315$, an epidemic pathogen of cystic fibrosis patients. J Bacteriol 191, 261-277.

Kaneko, T., Sato, S., Kotani, H., Tanaka, A., Asamizu, E., Nakamura, Y., Miyajima, N., Hirosawa, M., Sugiura, M. \& other authors (1996). Sequence analysis of the genome of the unicellular cyanobacterium Synechocystis sp. strain PCC6803. II. Sequence determination of the entire genome and assignment of potential protein-coding regions. DNA Res 3, 109-136.

Koedam, N., Wittouck, E., Gaballa, A., Gillis, A., Hofte, M. \& Cornelis, P. (1994). Detection and differentiation of microbial siderophores by isoelectric focusing and chrome azurol S overlay. Biometals 7, 287-291.

Kovach, M. E., Phillips, R. W., Elzer, P. H., Roop, R. M., II \& Peterson, K. M. (1994). pBBR1MCS: a broad-host-range cloning vector. Biotechniques 16, 800-802.

Kovach, M. E., Elzer, P. H., Hill, D. S., Robertson, G. T., Farris, M. A., Roop, R. M., II \& Peterson, K. M. (1995). Four new derivatives of the broad-host-range cloning vector pBBR1MCS, carrying different antibiotic-resistance cassettes. Gene 166, 175-176.

Kumar, S., Tamura, K. \& Nei, M. (2004). MEGA3: Integrated software for molecular evolutionary genetics analysis and sequence alignment. Brief Bioinform 5, 150-163.

Lambalot, R. H. \& Walsh, C. T. (1995). Cloning, overproduction, and characterization of the Escherichia coli holo-acyl carrier protein synthase. J Biol Chem 270, 24658-24661.

Lambalot, R. H., Gehring, A. M., Flugel, R. S., Zuber, P., LaCelle, M., Marahiel, M. A., Reid, R., Khosla, C. \& Walsh, C. T. (1996). A new enzyme superfamily - the phosphopantetheinyl transferases. Chem Biol 3, 923-936.

LiPuma, J. J. (1998). Burkholderia cepacia-management issues and new insights. Clin Chest Med 19, 473-486.

Lu, Y.-W., San Roman, A. K. \& Gehring, A. M. (2008). Role of phosphopantetheinyl transferase genes in antibiotic production by Streptomyces coelicolor. J Bacteriol 190, 6903-6908.

Mahenthiralingam, E., Baldwin, A. \& Vandamme, P. (2002). Burkholderia cepacia complex infection in patients with cystic fibrosis. J Med Microbiol 51, 533-538.

Mahenthiralingam, E., Urban, T. A. \& Goldberg, J. B. (2005). The multifarious, multireplicon Burkholderia cepacia complex. Nat Rev Microbiol 3, 144-156.

Mahenthiralingam, E., Baldwin, A. \& Dowson, C. G. (2008). Burkholderia cepacia complex bacteria: opportunistic pathogens with important natural biology. J Appl Microbiol 104, 1539-1551.

Marahiel, M. A., Stachehaus, T. \& Mootz, H. D. (1997). Modular peptide synthetases involved in nonribosomal peptide synthesis. Chem Rev 97, 2651-2674.

May, J. J., Wendrich, T. M. \& Marahiel, M. A. (2001). The $d h b$ operon of Bacillus subtilis encodes the biosynthetic template for the catecholic siderophore 2,3-dihydrobenzoate-glycine-threonine trimeric ester bacillibactin. J Biol Chem 276, 7209-7217.

Metcalf, W. W., Jiang, W. \& Wanner, B. L. (1994). Use of the rep technique for allele replacement to construct new Escherichia coli hosts for maintenance of $\mathrm{R} 6 \mathrm{~K} \gamma$ origin plasmids at different copy numbers. Gene 138, 1-7.

Meyer, J.-M., Van, V. T., Stintzi, A., Berge, O. \& Winkelmann, G. (1995). Ornibactin production and transport properties in strains of Burkholderia vietnamiensis and Burkholderia cepacia (formerly Pseudomonas cepacia). Biometals 8, 309-317.

Miller, J. (1972). Experiments in Molecular Genetics. Cold Spring Harbor, NY: Cold Spring Harbor Laboratory Press.

Mootz, H. D., Finking, R. \& Marahiel, M. A. (2001). 4'Phosphopantetheine transfer in primary and secondary metabolism of Bacillus subtilis. J Biol Chem 276, 37289-37298.

Nakano, M. M., Corbell, N., Besson, J. \& Zuber, P. (1992). Isolation and characterization of $s f p$ : a gene that functions in the production of the lipopeptide biosurfactant, surfactin, in Bacillus subtilis. Mol Gen Genet 232, 313-321.

Quadri, L. E. N. (2000). Assembly of aryl-capped siderophores by modular peptide synthetases and polyketide synthetases. Mol Microbiol 37, 1-12.

Quadri, L. E. N., Sello, J., Keating, T. A., Weinreb, P. H. \& Walsh, C. T. (1998a). Identification of a Mycobacterium tuberculosis gene cluster encoding the biosynthetic enzymes for assembly of the virulenceconferring siderophore mycobactin. Chem Biol 5, 631-645.

Quadri, L. E. N., Weinreb, P. H., Lei, M., Nakano, M. M., Zuber, P. \& Walsh, C. T. (1998b). Characterization of Sfp, a Bacillus subtilis phosphopantetheinyl transferase for peptidyl carrier protein domains in peptide synthetases. Biochemistry 37, 1585-1595.

Quadri, L. E. N., Keating, T. A., Patel, H. M. \& Walsh, C. T. (1999). Assembly of the Pseudomonas aeruginosa nonribosomal peptide siderophore pyochelin: in vitro reconstitution of aryl-4,2-bisthiazoline synthetase activity from PchD, PchE and PchF. Biochemistry 38, 14941-14954.

Reik, R., Spilker, T. \& LiPuma, J. L. (2005). Distribution of Burkholderia cepacia complex species among isolates recovered from persons with or without cystic fibrosis. J Clin Microbiol 43, 2926-2928.

Reimmann, C., Serino, L., Beyeler, M. \& Haas, D. (1998). Dihydroaeruginoic acid synthetase and pyochelin synthetase, products of the $p c h E F$ genes are induced by extracellular pyochelin in Pseudomonas aeruginosa. Microbiology 144, 3135-3148.

Reimmann, C., Patel, H. M., Serino, L., Barone, M., Walsh, C. T. \& Haas, D. (2001). Essential PchG-dependent reduction in pyochelin biosynthesis of Pseudomonas aeruginosa. J Bacteriol 183, 813-820.

Reuter, K., Mofid, M. R., Marahiel, M. A. \& Ficner, R. (1999). Crystal structure of the surfactin synthetase-activating enzyme Sfp: a prototype of the $4^{\prime}$-phosphopantetheinyl transferase superfamily. EMBO J 18, 6823-6831.

Rinehart, K. L., Staley, A. L., Wilson, S. R., Ankenbauer, R. G. \& Cox, C. D. (1995). Stereochemical assignment of the pyochelins. $\mathrm{J} \mathrm{Org}$ Chem 60, 2786-2791.

Sambrook, J., Fritsch, E. F. \& Maniatis, T. (1989). Molecular cloning: $a$ laboratory manual. Cold Spring Harbor, NY: Cold Spring Harbor Laboratory Press.

Sanchez, C., Du, L., Edwards, D. J., Toney, M. D. \& Shen, B. (2001). Cloning and characterization of a phosphopantetheinyl transferase from Streptomyces verticillus ATCC15003, the producer of the hybrid peptide-polyketide antitumor drug bleomycin. Chem Biol 8, 725-738.

Schlegel, K., Taraz, K. \& Budzikiewicz, H. (2004). The stereoisomers of pyochelin, a siderophore of Pseudomonas aeruginosa. Biometals 17, 409-414.

Schwyn, B. \& Neilands, J. B. (1987). Universal chemical assay for the detection and determination of siderophores. Anal Biochem 160, 4756. 
Sieber, S. A. \& Marahiel, M. A. (2003). Learning from nature's drug factories: nonribosomal synthesis of macrocyclic peptides. J Bacteriol 185, 7036-7043.

Sieber, S. A. \& Marahiel, M. A. (2005). Molecular mechanisms underlying nonribosomal peptide synthesis: approaches to new antibiotics. Chem Rev 105, 715-738.

Simon, R., Priefer, U. \& Puhler, A. (1983). A broad host range mobilization system for in vivo genetic engineering: transposon mutagenesis in Gram-negative bacteria. Nat Biotechnol 1, 784-791.

Sokol, P. A. (1986). Production and utilization of pyochelin by clinical isolates of Pseudomonas cepacia. J Clin Microbiol 23, 560-562.

Sokol, P. A. \& Woods, D. E. (1988). Effect of pyochelin on Pseudomonas cepacia respiratory infection. Microb Pathog 5, 197-205.

Sokol, P. A., Lewis, C. J. \& Dennis, J. J. (1992). Isolation of a novel siderophore from Pseudomonas cepacia. J Med Microbiol 36, 184-189.

Sokol, P. A., Darling, P., Woods, D. E., Mahenthiralingam, E. \& Kooi, C. (1999). Role of ornibactin biosynthesis in the virulence of Burkholderia cepacia: characterization of $p v d A$, the gene encoding L-ornithine $N^{5}$ oxygenase. Infect Immun 67, 4443-4455.

Sokol, P. A., Darling, P., Lewenza, S., Corbett, C. R. \& Kooi, C. D. (2000). Identification of a siderophore receptor required for ferric ornibactin uptake in Burkholderia cepacia. Infect Immun 68, 65546560.

Sousa, S. A., Ramos, C. G., Almeida, F., Meirinhos-Soares, L., Wopperer, J., Schwager, S., Eberl, L. \& Leitao, J. H. (2008). Burkholderia cenocepacia J2315 acyl carrier protein: a potential target for antimicrobials' development. Microb Pathog 45, 331-336.

Speert, D. P. (2002). Advances in Burkholderia cepacia complex. Paediatr Respir Rev 3, 230-235.

Stephan, H., Freund, S., Beck, W., Jung, G., Meyer, J.-M. \& Winkelmann, G. (1993). Ornibactins - a new family of siderophores from Pseudomonas cepacia. Biometals 6, 93-100.

Thomas, M. S. (2007). Iron acquisition mechanisms of the Burkholderia cepacia complex. Biometals 20, 431-452.

Thompson, A. B., Bohling, T., Payvandi, F. \& Rennard, S. I. (1990). Lower respiratory tract lactoferrin and lysozyme arise primarily in the airways and are elevated in association with chronic bronchitis. J Lab Clin Med 115, 148-158.

Thompson, J. D., Higgins, D. G. \& Gibson, T. J. (1994). ClUSTAL W: Improving the sensitivity of progressive multiple sequence alignment through sequence weighting, position-specific gap penalties and weight matrix choice. Nucleic Acids Res 22, 4673-4680.

Uehlinger, S., Schwager, S., Bernier, S. P., Riedel, K., Nguyen, D. T., Sokol, P. A. \& Eberl, L. (2009). Identification of specific and universal virulence factors in Burkholderia cenocepacia strains by using multiple infection hosts. Infect Immun 77, 4102-4110.

Vandamme, P., Holmes, B., Vancanneyt, M., Coenye, T., Hoste, B., Coopman, R., Revets, H., Lauwers, S., Gillis, M. \& other authors (1997). Occurrence of multiple genomovars of Burkholderia cepacia in cystic fibrosis and proposal of Burkholderia multivorans sp. nov. Int J Syst Bacteriol 47, 1188-1200.

Visca, P., Ciervo, A., Sanfilippo, V. \& Orsi, N. (1993). Iron-regulated salicylate synthesis by Pseudomonas spp. J Gen Microbiol 139, 19952001.

Visser, M. B., Majumdar, S., Hani, E. \& Sokol, P. A. (2004). Importance of the ornibactin and pyochelin siderophore transport systems in Burkholderia cenocepacia lung infections. Infect Immun 72, 2850-2857.

Walsh, C. T., Gehring, A. M., Weinreb, P. H., Quadri, L. E. N. \& Flugel, R. S. (1997). Post-translational modification of polyketide and nonribosomal peptide synthases. Curr Opin Chem Biol 1, 309-315.

Wang, J., Lory, S., Ramphal, R. \& Jin, S. (1996). Isolation and characterization of Pseudomonas aeruginosa genes inducible by respiratory mucus derived from cystic fibrosis patients. Mol Microbiol 22, 1005-1012.

Wang, L., McVey, J. \& Vining, L. C. (2001). Cloning and functional analysis of a phosphopantetheinyl transferase superfamily gene associated with jadomycin biosynthesis in Streptomyces venezuelae ISP5230. Microbiology 147, 1535-1545.

Yanisch-Perron, C., Vieira, J. \& Messing, J. (1985). Improved M13 phage cloning vectors and host strains: nucleotide sequences of the M13mp18 and pUC19 vectors. Gene 33, 103-119.

Edited by: P. Cornelis 